\title{
Análise do perigo de incêndio: um estudo de caso na Comunidade de Amorim - Manguinhos/Rio de Janeiro
}

\section{Resumo}

Através de um estudo sobre as condições de segurança contra incêndio na Comunidade de Amorim, localizada no Rio de Janeiro, foi possível observar a falta de prevenção e proteção existente. Este artigo tem por objetivo identificar as deficiências encontradas nessa Comunidade em relação à segurança contra incêndio. Como resultado, apresentou-se um Mapa de Perigo de Incêndio, onde foi possível apontar os fatores que contribuem para a vulnerabilidade relacionada ao princípio e propagação de incêndio. Além disso, identificaramse as situações mais críticas que serviram como base para a capacitação dos moradores e aumento da percepção de risco de incêndio.

Palavras-chave: Amorim, incêndio, mapa de perigo de incêndio.

Itimamente o Brasil tem vivenciado fortes tragédias relacionadas à ocorrência de incêndios em assentamentos precários. No ano de 2012, em um intervalo de apenas três dias, foram reportadas pela mídia duas ocorrências em território nacional. Em 31 de agosto a Vila Sapo, localizada no bairro Serrano da cidade de Caxias do Sul, estado do Rio Grande do Sul, foi alvo de tragédia, pois o fogo atingiu 22 casas e vitimou três pessoas (DUARTE et al., 2012). Três dias depois, o cenário foi o Morro do Piolho, localizado na região de Campo Belo, zona sul da capital paulista. Neste último, não foram registradas vítimas fatais, porém o fogo destruiu vários barracos, deixando várias famílias desabrigadas (ZERO HORA, 2012). Mais

\section{Renata Batista Lucena}

Engenheira civil e mestranda de Engenharia Civil da Universidade Federal do Rio Grande do Sul (UFRGS), Avenida Osvaldo Aranha, 99, $3^{\circ}$ andar, CEP 90310-035, Porto Alegre, RS, (51) 3288-3172/ 8200-6594,rblucena@gmail.com

\section{Brena Miranda de Oliveira}

Estudante de arquitetura da Universidade de Caxias do Sul (UCS), Avenida Osvaldo Aranha, 99, $3^{\circ}$ andar, CEP 90310-035, Porto Alegre, RS, (51) 3308-4450 / (54) 8146-5350, brena_ferathy@ hotmail.com

\section{Eloisa Maria Adami Giazzon}

Arquiteta e mestranda de Engenharia Civil da Universidade Federal do Rio Grande do Sul (UFRGS), Avenida Osvaldo Aranha, 99, $3^{\circ}$ andar, CEP 90310-035, Porto Alegre, RS, (51) 3308-4450/ (54) 9976-4466, eloisagiazzon@gmail.com

\section{Alexandra Passuello}

Engenheira civil e professora doutora da Universidade Federal do Rio Grande do Sul (UFRGS), Avenida Osvaldo Aranha, 99, $3^{\circ}$ andar, CEP 90310-035, Porto Alegre, RS, (51) 3308-4450/ 9393-5090, alepassuello@gmail.com

\section{Cristiane Pauletti}

Engenheira civil e professora doutora da Universidade Federal do Rio Grande do Sul (UFRGS), Avenida Osvaldo Aranha, 99, $3^{\circ}$ andar, CEP 90310-035, Porto Alegre, RS, (51) 3308-4450/ 8107-2130, pauletti.cristiane@gmail.com

\section{Luiz Carlos Pinto da Silva Filho}

Engenheiro civil e professor PhD da Universidade Federal do Rio Grande do Sul (UFRGS), Avenida Osvaldo Aranha, 99, $7^{\circ}$ andar, CEP 90310-035, Porto Alegre, RS, (51) 3308-4450, Icarlos66@gmail.com

recentemente, em 27 de janeiro de 2013, na cidade de Porto Alegre - RS, um incêndio ocorrido na Vila Liberdade destruiu 50 casebres, entretanto outras 150 moradias foram afetadas devido à fumaça, sendo que muitas pessoas tiveram que ser atendidas devido aos problemas gerados pela inalação da fumaça (GALLISA, 2013).

Os assentamentos precários, formados a partir da ocupação espontânea e desordenada do território são caracterizados pela presença de edificações construídas sem padrão normativo, sendo muitas vezes mais vulneráveis a diversos tipos de sinistros, principalmente aqueles relacionados à ação do fogo. 
Samora (2009) afirma que a densidade de ocupação elevada nos assentamentos precários, através de ocupações indiscriminadas dos terrenos, com a consequente contiguidade das edificações, tem sido uma das causas do alastramento de incêndio nestes assentamentos.

Os incêndios que se desenvolvem em assentamentos precários, são muitas vezes de magnitudes consideráveis, visto que a grande maioria das edificações, além de estarem localizadas muito próximas uma das outras, são normalmente construídas com materiais altamente combustíveis. Somado a isso, os acessos às moradias, em geral, ocorrem através de vias estreitas, becos e escadarias que além de dificultar a ação dos bombeiros no combate ao incêndio, dificultam as rotas de fuga para evacuação. Tendo em vista estas condições, os danos podem ser muito extensos, ultrapassando em muitos casos o prejuízo relacionado à perda de bens materiais, ameaçando também a vida dos moradores.

A Comunidade de Amorim, localizado no município do Rio de Janeiro, é um dos assentamentos precários mais antigos do Complexo de Manguinhos. Segundo Lima (2010), o nome Amorim é em referência a João Dias Amorim, que foi o primeiro proprietário da Fazenda de Manguinhos, antigamente localizada na área na qual hoje a comunidade está estabelecida.

Os primeiros moradores que se estabeleceram em Amorim faziam parte do grupo de portugueses que imigraram para o Brasil naquele período, além das pessoas provenientes de residências precárias localizadas no centro do Rio de Janeiro e que, foram forçadas a deixarem o seu local de origem. Outro fator que auxiliou na consolidação desta Comunidade foi o inicio das atividades da Fundação Oswaldo Cruz (FIOCRUZ). Seus funcionários, grande maioria residentes da região central do Município, começaram a encontrar dificuldades de deslocamento e naturalmente buscaram ocupar regiões próximas ao local de trabalho. Sendo assim, o espaço localizado no entorno da Fundação foi aos poucos sendo ocupado pelas residências de seus trabalhadores.

Conforme os dados do último Censo, atualmente na comunidade de Amorim existem 4.776 habitantes, totalizando 1.232 domicílios divididos em três setores censitários (IBGE, 2010). A comunidade é caracterizada por um forte adensamento de edificações, embrenhadas entre becos e vielas que permitem somente o deslocamento de pedestres. A circulação de veículos é possível em uma única rua principal, mas que, no entanto, não possui saída. A única área verde ainda preservada faz parte de um lote inicial remanescente, mas que, no entanto observou-se que já se encontra em processo de reparcelamento do solo, com o surgimento de novas moradias no local.

As construções são, em geral, do tipo geminado, caracterizadas pela verticalização através de 2, 3 e, em alguns casos, até mesmo mais pavimentos. Grande parte dessas edificações possui reboco e pintura, entretanto apresenta outras precariedades relacionadas tanto ao sistema construtivo, quanto aos serviços públicos como abastecimento de água, saneamento e rede elétrica. O uso residencial predomina na comunidade, sendo que a presença de comércio e serviços está concentrada na via principal. É importante salientar que, mesmo de forma pontual, existem pontos de atividades comerciais vinculadas a algumas moradias localizadas no interior do assentamento.

Desse modo, o presente trabalho pretende desenvolver a análise das situações de perigo de incêndio na Comunidade de Amorim, considerando fatores que, nas legislações vigentes, influenciam na ocorrência e propagação de um incêndio. Além disso, foram também observados fatores que podem comprometer a capacidade de resposta na ocasião de um sinistro, gerados pela reduzida acessibilidade das equipes de combate ao incêndio. Esta pesquisa tem como contribuição a elaboração de um Mapa de Situações de Perigo de Incêndio da Comunidade de Amorim, através da espacialização dos pontos identificados como potenciais situações de risco. As situações consideradas mais críticas pelos pesquisadores serviram como base para a realização de uma capacitação da comunidade, com o objetivo de aumentar a percepção de risco de incêndio.

\section{Assentamentos precários}

Os assentamentos precários recebem diferentes nomes em todo o mundo: borgate, squatters, bidovilles, gourbvilles, barriadas, ranchos, ranchitos, pueblos jovenes, favela (NICO, 2010). 
O Ministério das Cidades (BRASIL, 2010) define assentamentos precários como áreas que têm uma ou mais das seguintes características: irregularidade fundiária ou urbanística; deficiência de infraestrutura; perigo a alagamentos, deslizamentos ou outros tipos de risco; altos níveis de densidade dos assentamentos e das edificações; precariedade construtiva das unidades habitacionais; enormes distâncias entre moradia e o trabalho; sistemas de transportes insuficientes, caros e com alto nível de desconforto e insegurança; inexistência ou deficiência dos serviços públicos (saneamento, educação e saúde).

Para Coelho (2012) favela é considerada conforme a definição feita por Davis (2006) como todo o tipo de abrigo precário: cortiço, hospedarias, invasões, loteamentos clandestinos, campo de refugiados e até "moradores de rua" o que resulta em 78\% da população mundial vivendo em favelas.

Nico (2010) corrobora a ideia do UN- Habitat Global Reports on Human Settlements 2003, que indica que uma em cada seis pessoas vive em favelas ao redor do mundo; e que em 2033, a relação poderá saltar para uma em cada três pessoas.

O processo de urbanização brasileiro, ocorrido no final do século XIX, trouxe para as cidades a presença maciça de camadas populares (VILLAÇA, 1998 apud SAMORA, 2009). Sendo assim, o problema das favelas no Brasil se iniciou nesse século, na cidade do Rio de Janeiro, e se intensificou em meados dos anos 1920 (COELHO, 2012).

Já em são Paulo, o processo de expansão das favelas ocorreu de forma menos acelerada até os anos 1970, quando estes assentamentos passaram a ser alternativa habitacional para os pobres da cidade. 0 lote periférico, muitas vezes clandestino ou irregular, deu origem ao padrão urbano configurador do modo de morar dos setores de baixa renda desta cidade (GROSTEIN, 1998 apud PULHEZ, 2007).

Segundo Samora (2009) é possível criar condições de moradia digna nas favelas desde que a caracterização das condições dos assentamentos, dados quanto à insolação nos domicílios, ao risco de incêndio e de quedas ou outras injúrias façam parte de um diagnóstico habitacional, visando garantir a qualidade mínima para todas as moradias.

\section{A segurança contra incêndio}

O termo Segurança Contra Incêndio (SCI) está relacionado a medidas que visam o controle do princípio e da propagação de um incêndio, contendo parâmetros básicos que devem ser considerados num projeto de uma edificação. Um sistema adequado de segurança contra incêndio deve ser selecionado tendo por base os potencias riscos para o início do incêndio, sua propagação e consequências. Do ponto de vista urbanístico, Monteiro (2010) define SCI como uma visão macro da ação de promoção da segurança contra o sinistro. São medidas e preceitos a serem desenvolvidos que colaboram com a segurança da edificação, bem como do espaço urbano.

Os autores Bukowiski et. al (1994) destacam que o objetivo geral da SCl é fornecer segurança contra incêndio através de um planejamento que foque na minimização dos danos promovidos pela ação do fogo, além de garantir uma rápida retomada das funções daquela edificação após a ocorrência de um sinistro. Os mesmos autores evidenciam que, os objetivos adjacentes do SCI podem ser definidos através da/o:

prevenção ao fogo;

. retardo do crescimento do fogo e propagação;

proteção dos ocupantes e edificação contra os decorrências do incêndio;

minimização do impacto do incêndio;

apoio às operações dos serviços de combate ao incêndio.

Matidieri (2008) ressalta que a prevenção contra incêndio é garantida através da adoção de medidas que se destinam a prevenir a ocorrência do início de incêndio. Já as medidas de proteção contribuem para limitar o crescimento e a propagação do incêndio, além de auxiliar na realização de uma evacuação segura do edifício, tomando precauções contra o colapso estrutural e propiciando eficiência e agilidade nas operações de combate e resgate.

Os condicionantes arquitetônicos e urbanísticos, bem como as características do meio no qual as edificações estão inseridas, são fatores que influenciam diretamente na concepção do sistema de SCI. A Secretaria de Assistência à Saúde do Ministério da Saúde (BRASIL, 1995) cita alguns condicionantes 
de prevenção que devem ser considerados nos meios urbanísticos:

clima e microclima (umidade do ar, índice pluviométrico, irradiação solar, concentração de chuvas e ventos dominantes etc.);

relação com às divisas da edificação, alinhamento e proximidade em relação a vizinhança;

dimensões das vias e condições de acesso;

abastecimento de água, posição de hidrantes públicos e condições da rede de energia elétrica;

distância do posto mais próximo do Corpo de Bombeiros, da polícia, bem como facilidades de acesso;

afastamento em relação a massas florestais;

trânsito nas proximidades (engarrafamento, semáforos, serviços de transporte coletivo, pontos de táxi, facilidades para evacuação).

\section{Levantamento do perigo de incêndio na Comunidade de Amorim}

O levantamento das situações de perigo de incêndio na Comunidade de Amorim foi realizado em duas fases, sendo a primeira classificada como exploratória e a segunda de caráter investigativo. A primeira fase foi constituída de uma visita técnica preliminar ao local de estudo e teve como objetivo a caracterização da comunidade e identificação das potencialidades de estudo do risco de incêndio. A segunda fase, no entanto, foi dividida em duas visitas técnicas, e teve como foco a identificação e localização das situações de perigo, tanto no contexto geral da comunidade, quanto nos casos pontuais.

A primeira visita ocorreu no mês de julho de 2012 e foi realizada por uma equipe de engenheiros civis. É importante salientar que durante a realização de todas as visitas, as atividades foram acompanhadas por moradores locais e representantes do Instituto Oswaldo Cruz (IOC), grupo fortemente ativo na comunidade.

Durante o percurso a equipe buscou conhecer o assentamento e identificar os principais aspectos observados em relação à precariedade das instalações elétricas, bem como os demais fatores que poderiam contribuir com o inicio de um possível incêndio e/ou agravamento dos danos provocados na ocorrência do mesmo. Para isso foi realizado um levantamento fotográfico dos pontos e situações com maiores agravantes. O Quadro 1 apresenta uma relação das principais situações de perigo de incêndio encontradas na Comunidade de Amorim, bem como a forma de incidência no aumento do perigo de incêndio.

A segunda fase foi feita entre os meses de julho e agosto de 2012, neste caso, porém, o trabalho foi

Quadro 1: Relação das principais situações de perigo de incêndio identificadas na Comunidade de Amorim.

\begin{tabular}{|c|c|c|}
\hline \multicolumn{2}{|c|}{ Situações de perigo de incêndio identificadas } & $\begin{array}{l}\text { Forma de incidência para o perigo de } \\
\text { incêndio }\end{array}$ \\
\hline \multirow{4}{*}{$\begin{array}{l}\text { Relacionadas à } \\
\text { acessibilidade interna }\end{array}$} & Largura reduzida dos becos & \multirow{7}{*}{$\begin{array}{l}\text { Dificulta a fuga dos moradores, resgate de } \\
\text { vítimas e combate ao fogo. }\end{array}$} \\
\hline & Obstáculos nos becos & \\
\hline & Rampas com declividades excessivas & \\
\hline & Becos úmidos pela falta de drenagem & \\
\hline \multirow{5}{*}{$\begin{array}{l}\text { Relacionadas às } \\
\text { edificações }\end{array}$} & Verticalização das edificações & \\
\hline & $\begin{array}{l}\text { Escadas com degraus de dimensões inadequadas e falta de } \\
\text { corrimão }\end{array}$ & \\
\hline & Presença de grades em portas e janelas & \\
\hline & Aberturas frontais das edificações & Propicia a propagação do fogo \\
\hline & $\begin{array}{l}\text { Adensamento das coberturas das edificações (proximidade } \\
\text { dos beirais) }\end{array}$ & Retenção da fumaça \\
\hline \multirow{2}{*}{$\begin{array}{l}\text { Relacionadas às } \\
\text { instalações e redes } \\
\text { elétricas }\end{array}$} & Fácil contato com a fiação elétrica & Choque elétrico \\
\hline & Ligação irregular & $\begin{array}{l}\text { Sobrecarga da rede elétrica e curto } \\
\text { circuito }\end{array}$ \\
\hline \multirow{2}{*}{$\begin{array}{l}\text { Relacionadas à explosão e } \\
\text { combustão }\end{array}$} & Alta carga de incêndio & Facilita o início do incêndio \\
\hline & Botijões de gás ao lado de bomba hidráulica & Explosão \\
\hline
\end{tabular}


Figura 1: Mapa temático do levantamento de perigo de incêndio realizado na Comunidade de Amorim. Fonte: imagem criada a partir de imagem extraída do Google Earth. realizado por uma equipe multidisciplinar, em um total de duas visitas. As visitas técnicas focaram no mapeamento físico das situações identificadas na primeira fase do estudo. As situações de perigo foram localizadas ao longo de toda comunidade e espacializadas em uma imagem de satélite extraída do Software Google Earth, conforme mostra a Figura 1. É importante salientar que o levantamento realizado focou-se na parte externa das edificações.

No mapeamento das situações de perigo foi mantido o padrão de classificação adotado na primeira fase deste estudo e apresentado no Quadro 1, incorporando ainda os potenciais para combate à incêndios. Para melhor representa-los no mapa foi definido uma cor distinta para cada categoria, conforme segue abaixo:

relacionadas aos potenciais para combate do incêndio: COR VERDE
. relacionadas à acessibilidade dentro da comunidade: COR LILÁS

relacionadas à explosão e combustão: COR LARANJA

relacionadas à instalação e redes elétricas: COR VERMELHA

relacionadas às edificações: COR AZUL

A imagem extraída do Google Earth foi utilizada como base principal para espacialização dos resultados, porém, para facilitar a identificação das ruas e vielas foi necessário incorporar à imagem uma base digital de dados com vetorização das edificações e acessos. Este procedimento se tornou necessário, pois em assentamentos precários caracterizados por intenso adensamento, as coberturas das edificações acabam se sobrepondo uma às outras, impossibilitando a visualização dos acessos através exclusivamente da imagem do Google Earth.

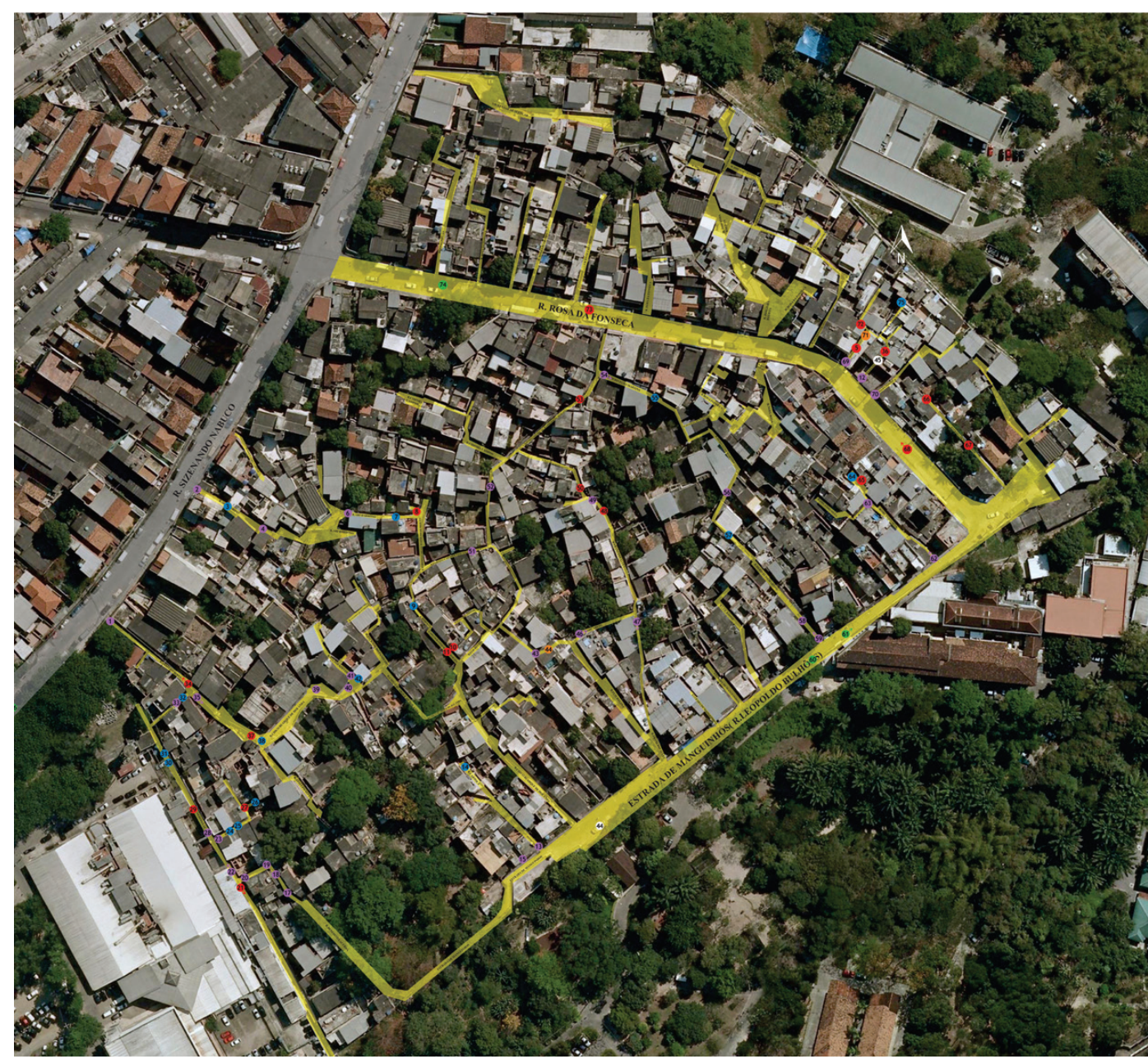


Figura 2: Único equipamento de segurança contra incêndio identificado em Amorim Rua Sizenando Nabuco, próximo à entrada da FIOCRUZ. Fonte: foto de Renata Batista Lucena.

Figura 3: Rua Rosa da Fonseca - presença de obstáculos que impedem o acesso de veículos de grande porte. Fonte: foto de Renata Batista Lucena.
A legenda do mapa produzido fisicamente foi caraterizada pelos números das situações de incêndio, acompanhado pela foto representativa e descrição da mesma.

\section{Situações de perigo relacionadas aos potencias para combate do incêndio}

Em relação aos potenciais para o combate ao incêndio, encontraram-se duas situações que podem contribuir diretamente na magnitude dos danos causados na ocorrência de um incêndio, sendo estas, a presença de somente um hidrante urbano, e insuficiência da presença de ruas com dimensões adequadas para o trânsito de veículos de combate ao fogo.

O único hidrante urbano localizado em Amorim encontra-se no início da principal via de acesso à comunidade (Figura 2), sendo que a presença de somente um equipamento impossibilita que o combate ao fogo possa ser realizado por mais de um caminhão. Além disso, alguns pontos da comunidade estão localizados aproximadamente 400 metros de distância, tornado impossível o alcance do jato de água. Em função disto, constata-se uma capacidade de resposta reduzida por parte das equipes do Corpo de Bombeiros, criando condições favoráveis para que um evento possa assumir proporções catastróficas.

Conforme é possível visualizar na Figura 1, a Comunidade de Amorim é caracterizada por um grande adensamento de ruelas de larguras muito reduzidas, sendo que as únicas duas ruas que permitem o acesso de veículos são a Rua Sizenando Nabuco e a Rua Rosa da Fonseca. Durante as visitas, contatou-se que estas ruas encontram-se parcialmente obstruídas, devido à presença de inúmeros obstáculos, que dificultam a passagem, principalmente de veículos de grande porte como o caminhão do corpo de bombeiros (Figura 3). Os obstáculos identificados estão relacionados aos mais diversos motivos, como por exemplo, estacionamento irregular de carros de moradores e outros usuários, bem como a presença de entulhos e uso inadequado da via pública através da extensão da propriedade privada.

\section{Situações de perigo relacionadas à acessibilidade}

A acessibilidade na Comunidade de Amorim foi o fator mais crítico observado, visto que a falta do acesso adequado abrange praticamente todo o assentamento. A Figura 4 evidencia a presença de acessos extremamente estreitos e de largura irregular, inclusive com a presença de objetos e instalações que bloqueiam o caminho. Além disso, devido a topografia acidentada da região, percebe-se a presença de inúmeras rampas, que em alguns casos apresentam declividades excessivas (Figura 5). É importante salientar que a precariedade do sistema de drenagem acaba favorecendo a formação de limo, deixando o piso escorregadio e aumentando ainda mais o risco de
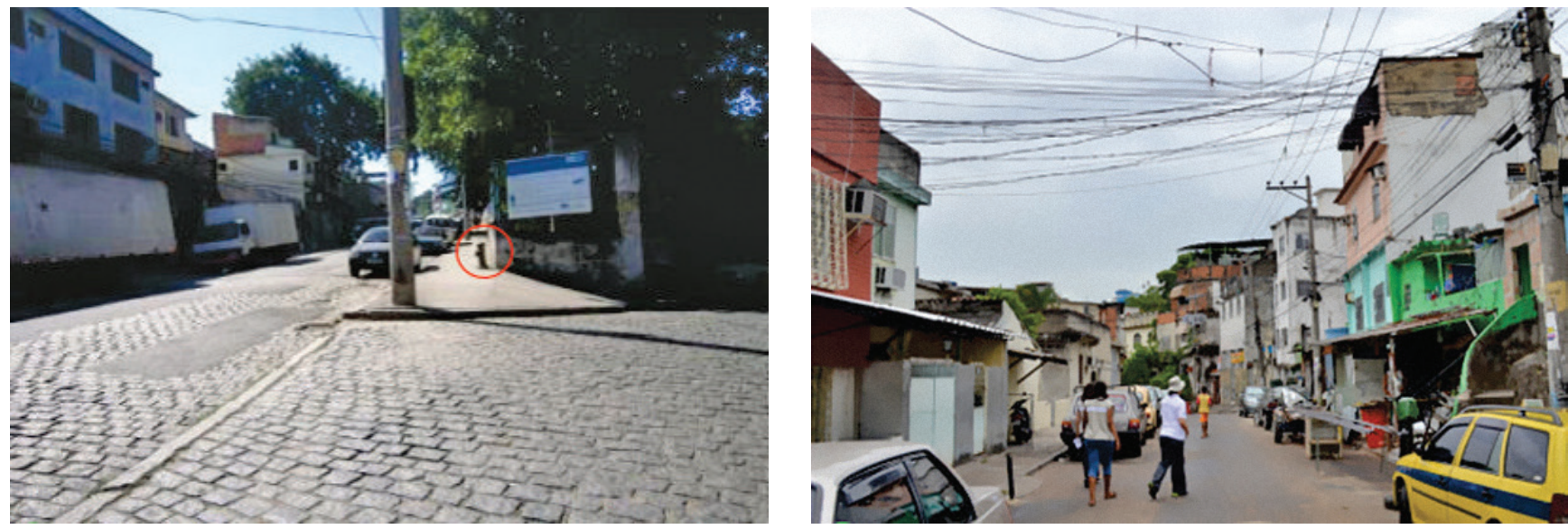


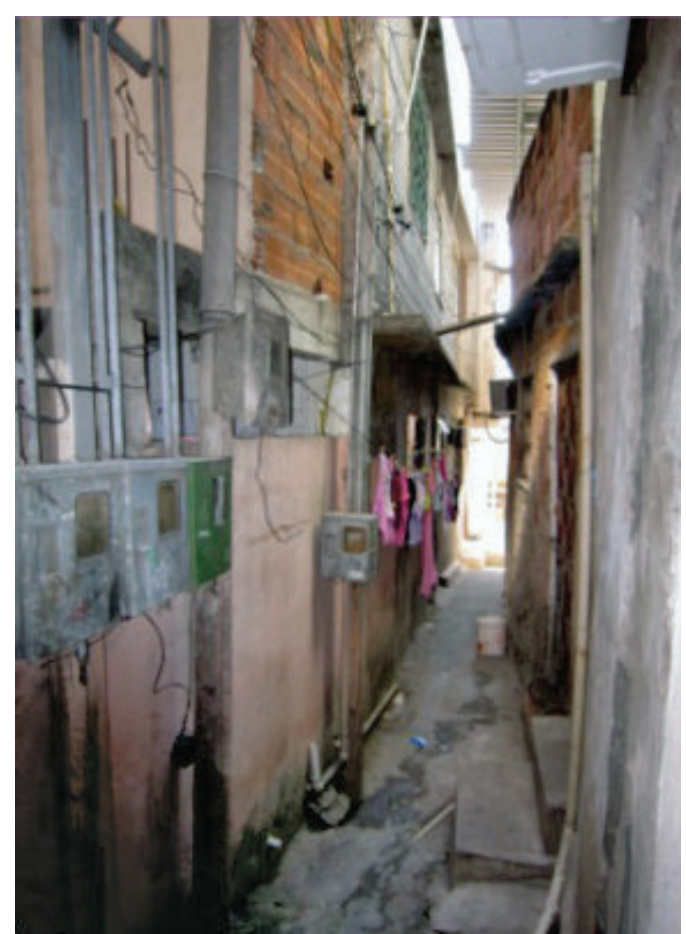

Figura 4: Beco estreito, largura irregular e presença de obstáculos. Fonte: foto de Renata Batista Lucena.

Figura 5: Beco com rampa de declividade excessiva. Fonte: foto de Renata Batista Lucena. quedas de pessoas. Em caso de fuga por um sinistro de incêndio, a livre passagem é fundamental para a dissipação rápida das pessoas, sendo que com a presença de obstáculos e diminuição da aderência do pavimento, a evasão pode ser fortemente dificultada.

\section{Situações de perigo relacionadas às características das edificações}

As edificações localizadas na Comunidade de Amorim fazem parte de um processo de autoconstrução, onde o projeto, além de não ter embasamento na legislação pertinente, é elaborado em função das necessidades momentâneas, bem como do espaço disponível, sendo estes fatores dinâmicos e mutáveis no tempo. Sendo assim, se evidencia a presença constante de adaptações construtivas que afetam tanto o espaço público, como também o conforto e utilização da edificação pelo próprio usuário.

Os elementos que constituem as edificações de Amorim se configuram como um berço de obstáculos para a fuga de pedestres. A Figura 6 exemplifica a problemática associada com as escadarias encontradas na comunidade, que na sua grande maioria são caracterizadas por degraus de dimensões reduzidas, incidindo diretamente

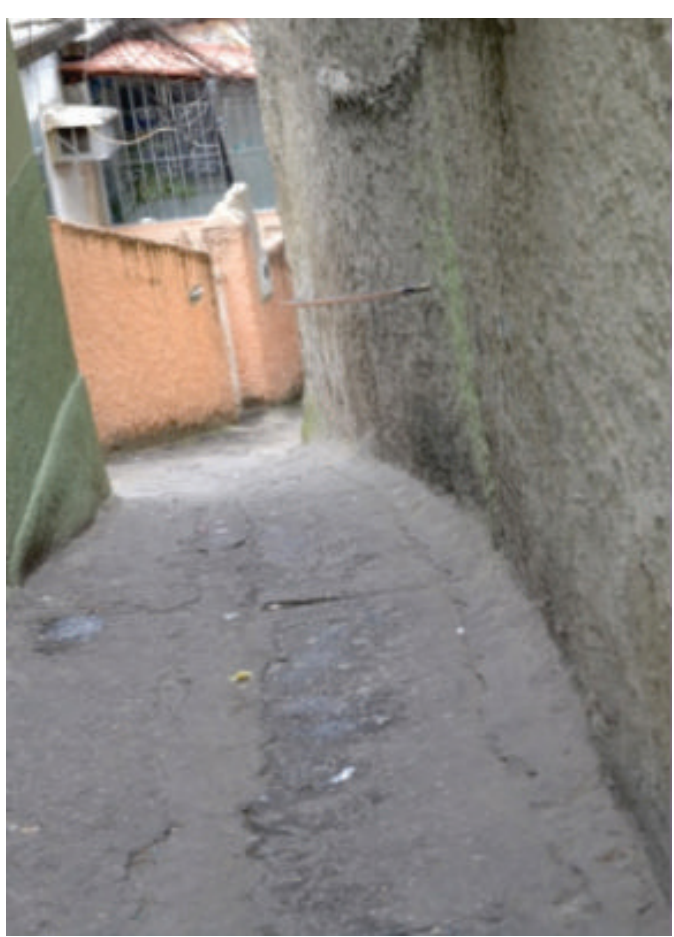

no aumento do risco de queda, principalmente em situações em que a pressa e o pânico estão presentes. Outro ponto importante observado está relacionado com os elementos utilizados para garantir a segurança pessoal e do patrimônio, como grades e portões, que também podem reduzir a possibilidade de fuga dos moradores. A Figura 7 apresenta uma das residências que exemplificam esta problemática, contendo proteção de grades em todas as suas aberturas, sem considerar saídas alternativas para casos de fuga.

Outro padrão observado em Amorim está relacionado à configuração das aberturas frontais das edificações, que, além de estarem localizadas muito próximas às edificações adjacentes, são posicionadas uma de frente para outra, conforme mostra as Figuras 8 e 9. Este tipo de padrão construtivo é um fator agravante na presença de fogo, pois favorece a propagação das chamas entre edificações vizinhas por essas aberturas, tornando quase impossível o isolamento do incêndio no interior da própria edificação. Somado a isso, o adensamento das edificações força a proximidade dos beirais das coberturas de moradias vizinhas, fator que, em caso de sinistro, pode causar a dificuldade de dispersão da fumaça, bloqueando o percurso utilizado para a fuga. 

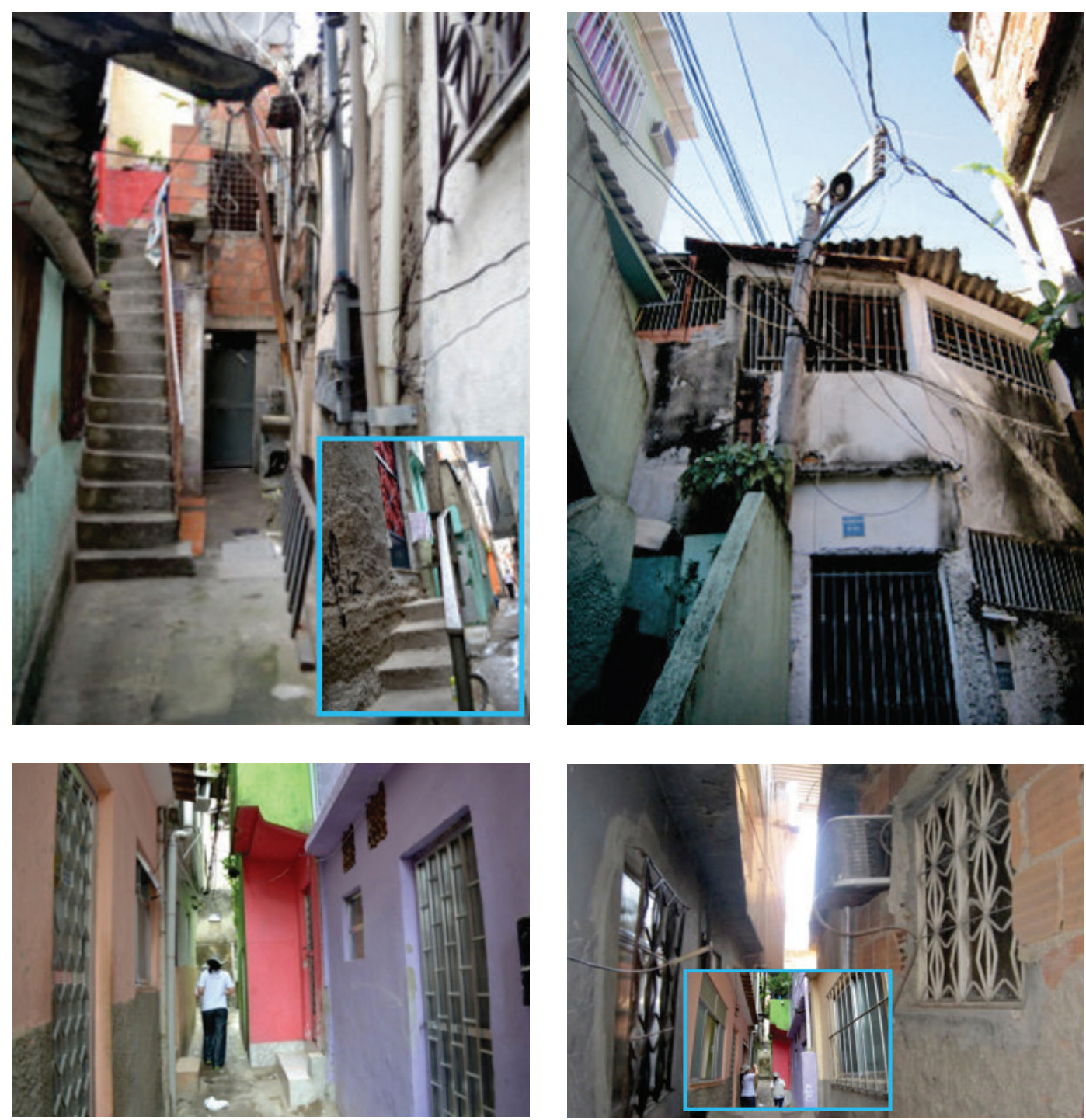

Figura 6: Escada de dimensões inadequadas. Fonte: foto de Renata Batista Lucena.

Figura 7: Presença de grades nas aberturas. Fonte: foto de Renata Batista Lucena.

Figura 8: Portas das residências frontais posicionadas de forma a facilitar a propagação das chamas. Fonte: foto de Renata Batista Lucena.

Figura 9: Janelas das residências frontais posicionadas de forma a facilitar a propagação das chamas. Fonte: foto de Renata Batista Lucena.

\section{Situações de perigo relacionadas às instalações e redes elétricas}

O fator de perigo de incêndio identificado como mais crítico na comunidade de Amorim está relacionado coma rede elétrica. As instalações irregulares são normalmente presenças constantes em assentamentos precários, visto a falta de um serviço adequado e fiscalização dos órgãos competentes. O sobrecarregamento da rede elétrica, devido às instalações irregulares, podem desencadear curtos circuitos que poderão contribuir no desenvolvimento de um incêndio. A Figura 10 exemplifica bem esta situação, onde é possível perceber a presença de uma aglomeração de fios provenientes de ligações irregulares/clandestinas.
Além dos famosos "gatos", foi possível observar situações mais críticas, como apresentado na Figura 11 , onde se visualiza a inserção da infraestrutura elétrica na própria edificação. Em situações como estas, a exposição direta com o transformador e a fiação elétrica, deixa os moradores totalmente vulneráveis a choques elétricos. Até mesmo quando a fiação encontra-se na parte externa da edificação (Figura 12), percebeu-se que os fios estão posicionados a alturas inadequadas, sendo que em alguns casos encontram-se também apoiados nas próprias janelas das edificações. Nestes casos, até mesmo as pessoas mais baixas, e principalmente as crianças, ficam totalmente expostas a um possível choque elétrico. 

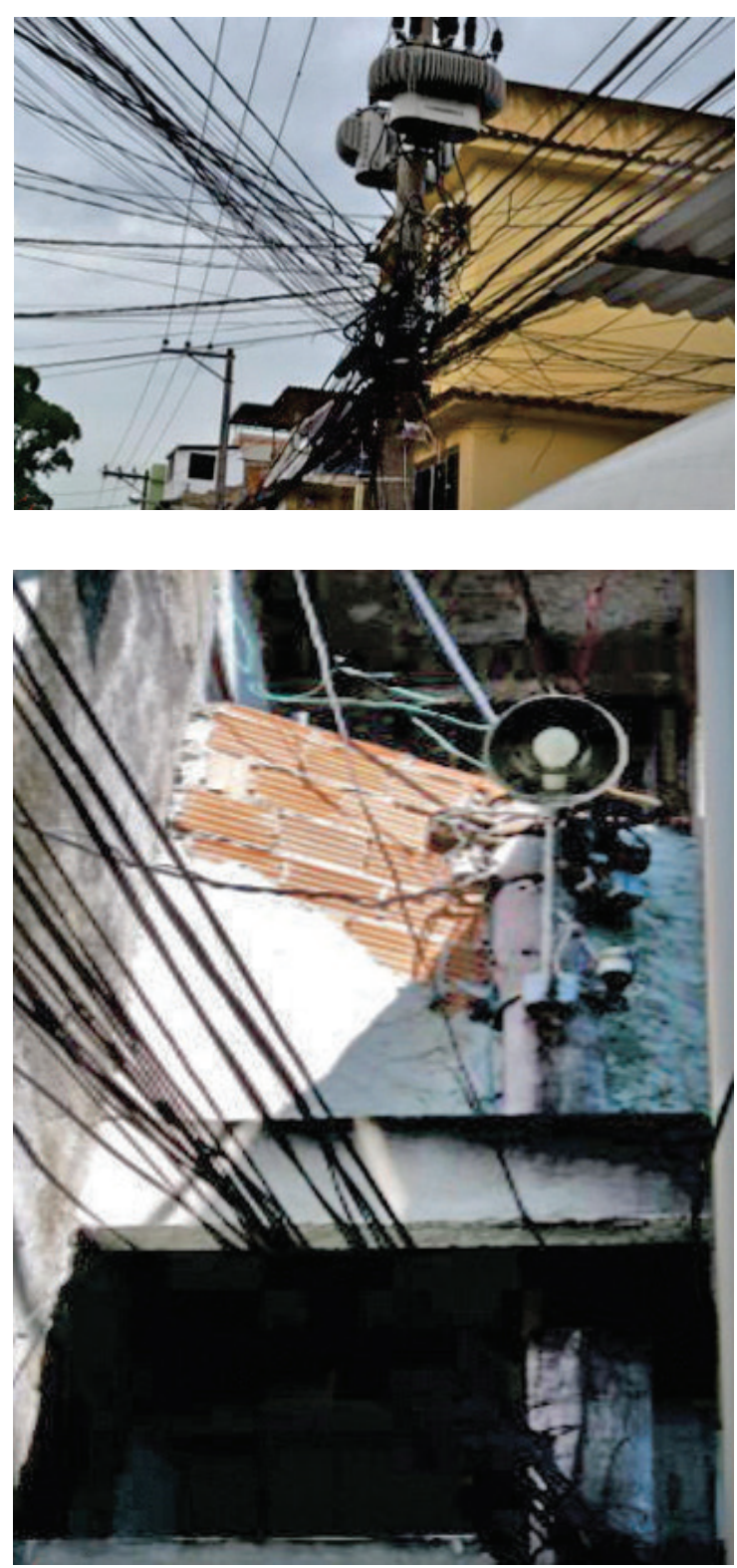

Figura 10: Ligação irregular

da rede elétrica - Rua Rosa da Fonseca. Fonte: foto de Renata Batista Lucena.

Figura 11: Detalhe da infraestrutura elétrica inserida na edificação. Fonte: foto de Renata Batista Lucena.

Figura 12: Fiação elétrica apoiada na janela da edificação. Fonte: foto de Renata Batista Lucena.

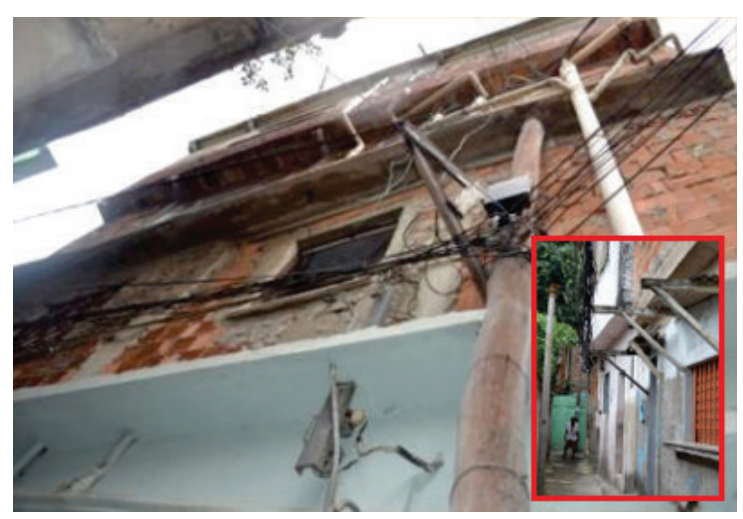




\section{Situações de perigo relacionadas à explosão e combustão}

Os assentamentos precários são caracterizados pela ineficiência e precariedade das redes de infraestrutura de muitos dos serviços públicos oferecidos. Esta situação acaba impactando na forma como uma comunidade evolui socialmente através de modificações no ambiente construído, podendo contribuir com adaptações alternativas para a solução de alguns destes problemas.

Na parte mais elevada da Comunidade de Amorim, localizada no cruzamento das ruas Sizenando Nabuco e Rosa da Fonseca, muitas residências apresentam dificuldades de abastecimento de água potável devido à baixa pressão na tubulação. Para solucionar este problema, os moradores instalaram bombas hidráulicas na parte externa das suas edificações.

Durante a visita técnica, foi identificada a presença de alguns botijões de gás posicionados no lado da bomba hidráulica, sem a existência de qualquer isolamento entre eles (Figura 13). Na existência de um vazamento de gás e seu acúmulo, qualquer tipo de faísca causada pelo funcionamento da bomba poderia provocar uma explosão dos botijões. Esta situação, mesmo sendo evidenciada de forma isolada em Amorim, mostra o quanto a população é carente em relação à percepção do risco no qual estão sendo expostas.
Já em relação ao acúmulo de resíduos, outras situações potencialmente perigosas foram identificadas na comunidade de Amorim. O recolhimento do lixo ocorre em um ponto específico da comunidade, sendo que o mesmo é realizado através do esvaziamento do container mantido na Estrada de Manguinhos. Durante a visita técnica foi possível constatar que a presença de somente um container é insuficiente para comportar os resíduos gerados pela comunidade. O excesso de lixo, sem nenhum tipo de separação, acaba sendo deixado inadequadamente ao lado do container, conforme pode ser visto na Figura 14. A presença de qualquer elemento desencadeador do fogo poderá favorecer a propagação de um incêndio de proporções consideráveis, visto a possibilidade de poder existir algum material caracterizado com alta carga de incêndio.

\section{Soluções para reduzir o perigo de incêndio}

A ocorrência de um incêndio em Amorim é uma ameaça que abrange toda a comunidade e devido às suas características de ocupação, os impactos gerados podem ser consideráveis. O forte adensamento das edificações é distribuído ao longo de toda a área, com uma configuração urbana caracterizada pela presença de um labirinto de acessos estreitos, interligados entre eles e, em muitos casos, sem saída.
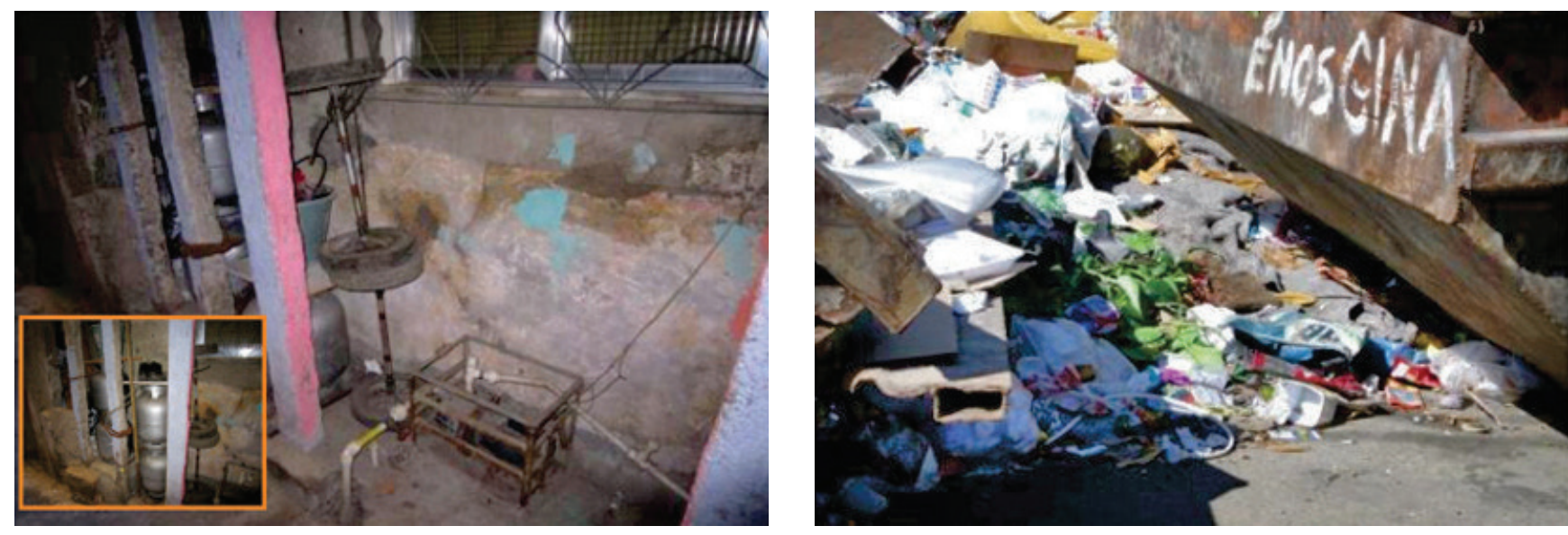
Nos processos de regularização fundiária de assentamentos precários, como o caso da comunidade de Amorim, medidas relacionadas à segurança quanto ao perigo de incêndio devem ser estudadas em função desta realidade. Como alternativa emergencial para a redução dos possíveis danos nos acessos mais estreitos, é necessário considerar a alocação de extintores portáteis espaçados a cada 20 metros, instalados em locais protegidos contra intempéries e danos físicos.

Outra solução simples que impactaria positivamente na redução do risco está relacionada com a identificação das rotas de fuga, através da demarcação do trajeto com sinalizações e iluminação de emergência. A identificação visual do caminho facilita a localização dos equipamentos de combate, orienta as equipes do corpo de bombeiros, bem como os próprios moradores, que em um momento de tensão podem se sentir desorientados e não encontrar rapidamente a saída mais adequada. É importante salientar que os textos escritos ou símbolos das placas sinalizadoras devam ter um nível de iluminação que garanta eficiente visibilidade, quando necessário.

Em Amorim prevalece o uso residencial, porém, existem também atividades voltadas para o comércio e serviços, principalmente na rua de acesso principal, Rua Rosa da Fonseca. A instalação de extintores nas edificações voltadas para esse tipo de uso, conforme exigem as legislações, também pode contribuir para a rápida extinção do fogo caso ocorra um princípio de incêndio.

As escadas de acesso à entrada das edificações são em geral mal dimensionadas e sem a presença de elementos que auxiliam a segurança dos usuários. A instalação de corrimões, bem como a aplicação de faixas antiderrapantes nos degraus, são alterativas rápidas que também contribuem para facilitar a fuga dos moradores.

Uma providência que deve ser tomada de imediato é o isolamento dos botijões de gás e da bomba hidráulica, pois a proximidade destes dois elementos gera um grave perigo de explosão. A construção de uma caixa de proteção, tanto para a bomba hidráulica, quanto para os botijões, já seriam suficientes para diminuir o perigo de explosão. No entanto, é importante que as caixas de proteção possuam ventilação direta para o espaço livre exterior, essa ventilação pode ser através de veneziana, tela ou similar, uma vez que, esses equipamentos não podem ficar confinados e sem ventilação.

As alternativas citadas acima são soluções simples e que podem ser realizadas pelos próprios moradores, entretanto, constatou-se a presença de muitas situações perigosas que para a sua solução demandaria parcerias externas e solicitações junto aos órgãos públicos, tais como:

. com relação à rede elétrica, fator crítico evidenciado na comunidade, é necessário ações voltadas à regularização das instalações elétricas pelos órgãos competentes. Para isso, a comunidade deve estar ciente que alterações autônomas nas instalações elétricas externas, por parte dos moradores, poderão causar a sobrecarga da rede e, como consequência, o aumento da suscetibilidade à ocorrência de incêndios. Isto poderia ser viabilizado através de campanhas educativas, focadas na qualificação da percepção de risco e acompanhada por uma fiscalização mais efetiva dos setores competentes;

. a criação de uma brigada de incêndio na comunidade, composta pelos próprios moradores, ajudaria na minimização de um incêndio dentro da comunidade, visto que os mesmos seriam capacitados de atuar no primeiro momento, podendo reduzir significativamente os danos causados até a chegada do Corpo de Bombeiros. A estação do Corpo de Bombeiros mais próxima de Amorim está localizada no Bairro Benfica, cuja distância aproximada é de $3 \mathrm{~km}$. Em horários normais, ou seja, fora da hora de pico, o tempo de deslocamento seria de 7 minutos, porém este tempo pode aumentar significativamente nos horários de maior movimento.

Considerando que muitas das situações potenciais de incêndios verificadas em Amorim poderiam ser mitigadas através do envolvimento comunitário, o trabalho buscou promover uma reflexão sobre identificação de risco com fins a qualificação da percepção de risco da comunidade. Visto que ações simples, realizadas pelos próprios moradores já seriam suficientes para reduzir a susceptibilidade e vulnerabilidade relacionadas ao risco de incêndio, foi realizada capacitação de um 
grupo de moradores da comunidade, focando no tema segurança contra incêndio.

\section{Conclusões}

Através deste estudo preliminar, foi possível constatar os principais aspectos relacionados ao risco de incêndio em assentamentos precários, sendo estes caracterizados por um alto adensamento das edificações e precariedade dos serviços essenciais.

No Mapa de Perigo de Incêndio de Amorim é possível identificar todas as deficiências relacionadas à segurança contra incêndio, sendo este uma ferramenta importante na identificação e qualificação da percepção de risco local. As situações perigosas foram dividas em 4 grupos, sendo estes relacionados às características arquitetônicas (residências), urbanas (acessos), rede elétrica e situações propicias à ocorrência de explosões e combustão.

Os potenciais de incêndio mais críticos estão relacionados às ligações elétricas irregulares, visto que as instalações irregulares estão presentes em todo assentamento. Em alguns destes pontos o adensamento habitacional incorporou às próprias edificações os equipamentos externos da rede elétrica.

Com relação à segurança contra incêndio na Comunidade, notou-se que é inexistente a presença de medidas de prevenção e proteção contra incêndio, visto que foi constatado em toda comunidade a susceptibilidade ao inicio de um incêndio, como da vulnerabilidade associada à propagação do mesmo. Somado a isso, o acesso e a mobilidade no interior do assentamento são muito deficientes, podendo incidir diretamente na perda de vidas humanas devido à ineficiência da rota de fuga.

Considera-se que a capacitação realizada com alguns moradores foi uma atividade oportuna e é de extrema importância, pois qualifica a percepção de risco, reduzindo a vulnerabilidade da comunidade.

\section{Referências bibliográficas}

BRASIL, Ministério da Saúde (1995). Secretaria de Assistência à Saúde. Série Saúde e Tecnologia: Texto de Apoio à Programação Física dos Estabelecimentos
Assistenciais de Saúde - Condições de Segurança Contra Incêndio. Brasília, p.:107, 1995.

BRASIL, Ministério das Cidades (2010). Ações Integradas de Urbanização de Assentamentos Precários. Edição Bilíngue, Brasília/ São Paulo, $1^{\text {a }}$ edição, p. 210, 2010.

COELHO, E. C. R. Sistema de Informações para Habitação Social na cidade de São Paulo: Habisp: apoio estratégico para gestão social. 2012. Tese (Doutorado em Geografia Humana) - Universidade de São Paulo, 2012

BUKOWSKI, R. W.; Babrauskas, V. Developing Rational, Performance-based Fire Safaty: Requirements in Model Building Codes. Fire and Materials. 1994 v. 18, p.: 173-191

DUARTE, A. et al. Fogo começou na casa dos três irmãos. Pioneiro, Caxias do Sul. n. 11.452, p.: 4-16 e 20-22, 01 e 02 Set. 2012

GALLISA, C. Incêndio atinge casas em vila próxima à Arena do Grêmio. G1 Rio Grande do Sul - RBSTV. Disponível em: < http://g1.globo.com/rs/rio-grandedo-sul/noticia/2013/01/incendio-atinge-casas-emvila-proxima-arena-do-gremio.html>. Acesso em: 01 fev. 2013

IBGE, Instituto Brasileiro de Geografia e Estatística (2011). Base de Informações do Censo 2010 por Setores Censitários. IBGE: 2011. Disponível em: <http:// www.censo2010.ibge.gov.br/sinopseporsetores/> Acesso em: 4 dez. 2012

LIMA, C. M. (org.). Território, participação popular e saúde: Manguinhos em debate. Rio de Janeiro : ENSP/ Fiocruz, 2010. 104 p.

MITIDIERI , M. L. O Comportamento dos materiais componentes construtivos diante do fogo: Reação ao Fogo. In: SEITO, A. I. et al. (Coord.). A segurança contra incêndio no Brasil. São Paulo: Projeto Editora, 2008. Cap. V, p.: 55-75

MONTEIRO, S. D. Análise de risco de incêndio aplicada ao Centro Histórico de Cuiabá. 2010. Monografia (Curso de Especialização em Engenharia de Segurança do Trabalho) - Universidade Federal do Mato Grosso. 2010.

NICO, A. P. F. O desenho urbano pautado pela infraestrutura urbana. 2010. Dissertação (Mestrado em Arquitetura e Urbanismo) - Universidade de São Paulo. 2010.

PULHEZ, M. M. Espaço de favela, fronteiras do ofício: história e experiência contemporâneas de arquitetos em assessorias de urbanização. 2007. Dissertação (Mestrado em Arquitetura e Urbanismo) - Universidade de São Paulo. 2007

SAMORA. P. R. Projetos de Habitação e Favelas: especificidades e parâmetros de qualidade. 2010. Tese (Doutorado em Arquitetura e Urbanismo) - Universidade de São Paulo. 2010.

ZERO HORA. Incêndio consome favela na zona sul da capital paulista. Disponível em: <http://zerohora.clicrbs com.br/rs/geral/noticia/2012/09/incendio-consomefavela-na-zona-sul-da-capital-paulista-3873724 html>. Acesso em 01 fev. 2013 